\title{
Piezo-assisted nuclear transfer affects cloning efficiency and may cause apoptosis
}

\author{
Yang Yu ${ }^{1,3}$, Chenhui Ding ${ }^{1,2,3}$, Eryao Wang ${ }^{1,3}$, Xinjie Chen ${ }^{1,3}$, Xuemei $\mathrm{Li}^{1,3}$, Chunli Zhao ${ }^{1}$, \\ Yong Fan ${ }^{1}$, Liu Wang ${ }^{1}$, Nathalie Beaujean ${ }^{4}$, Qi Zhou ${ }^{1}$, Alice Jouneau ${ }^{1,4}$ and Weizhi Ji ${ }^{2}$ \\ ${ }^{1}$ State Key Laboratory of Reproductive Biology, Institute of Zoology, Chinese Academy of Sciences, Beijing 100080, \\ China, ${ }^{2}$ Department of Reproduction and Development, Kunming Institute of Zoology and Kunming Primate Research \\ Center, Chinese Academy of Sciences, Kunming, Yunnan, China, ${ }^{3}$ Graduate University of Chinese Academy of \\ Sciences, Beijing, China and ${ }^{4}$ INRA, UMR 1198; ENVA; CNRS, FRE 2857, Biologie du Développement et \\ Reproduction, Jouy en Josas 78350, France
}

Correspondence should be addressed to A Jouneau who is now at Institute of Zoology, Chinese Academy of Sciences, Beijing 100080, China; Email: alice.jouneau@jouy.inra.fr or W Ji who is now at Kunming Primate Research Center and Kunming Institute of Zoology, Chinese Academy of Sciences, Kunming, Yunnan 650223, China; Email: wji@mail.kiz.ac.cn

Y Yu and C Ding contributed equally to this work

\begin{abstract}
Even though it generates healthy adults, nuclear transfer in mammals remains an inefficient process. Mainly attributed to abnormal reprograming of the donor chromatin, this inefficiency may also be caused at least partly by a specific effect of the cloning technique which has not yet been well investigated. There are two main procedures for transferring nuclei into enucleated oocytes: fusion and piezoelectric microinjection, the latter being used mostly in mice. We have, therefore, decided to compare the quality and the developmental ability, both in vivo and in vitro, of embryos reconstructed with electrofusion or piezoelectric injection. In addition, the effect of piezo setups of differing electric strengths was investigated. Along with the record of the rate of development, we compared the nuclear integrity in the blastomeres during the first cleavages as well as the morphological and cellular quality of the blastocysts. Our results show that the piezo-assisted micromanipulation can induce DNA damage in the reconstructed embryos, apoptosis, and reduced cell numbers in blastocysts as well as a lower rate of development to term. Even if piezo-driven injection facilitates a faster and more efficient rate of reconstruction, it should be used with precaution and with as low parameters as possible.
\end{abstract}

Reproduction (2007) 133 947-954

\section{Introduction}

Although it can result in apparently healthy adults, somatic cell nuclear transfer (SCNT) is a very inefficient process. The success rates of SCNT average $1-3 \%$ in most mammalian species (Solter 2000, Perry 2004). Even for mice, which were successfully cloned for the first time 8 years ago (Wakayama et al. 1998), few laboratories have reported the generation of cloned offspring. SCNT can be capricious and is still far from becoming a routine technique (Perry \& Wakayama 2002).

The low efficiency of SCNT has been attributed mostly to inefficient reprograming of the transferred nucleus (Jouneau \& Renard 2003, Latham 2004). More recently, it has been shown that the somatic cytoplasm transferred along with the nucleus has a detrimental effect on the subsequent development of the embryo
(Van Thuan et al. 2006). However, the specific effect of the cloning technique has been poorly investigated. There are two main procedures to transfer the 'donor' nuclei into enucleated oocytes: fusion and piezoelectric microinjection (PEM). In the first case, the membrane of the donor cell is fused with that of the oocyte by an electric current, a virus, or a chemical agent; whereas in the second case, the cytoplasmic membrane is broken and the donor nucleus is injected into the oocyte cytoplasm. While the electrofusion (EF) method is extensively used for most species, the PEM method is mainly applied in rodents.

Indeed, the first cloned mice derived from somatic cells were obtained in 1998 using PEM (Wakayama et al. 1998), but in 2000, generation of SCNT mice using the EF method was also reported (Ogura et al. 2000). Although both methods can be used to produce 
live animals, it is still unclear which method is the safer and more efficient. Galli et al. (2002) reported no difference between the two methods when comparing in vitro and in vivo developmental rates in cattle cloning. In the mouse, two groups have tried to address this question using fibroblasts (Ogura et al. 2000) and ES cells as donors (Yabuuchi et al. 2004) and have also reported no difference in the rate of development between the two methods. However, in both studies, the relatively small sample size makes it difficult to draw any definite conclusion. Moreover, the parameters' setup for the piezoelectric device was not taken into consideration. It is believed that the use of different piezoelectric strengths may account for the differences in cloning efficiency between laboratories. We therefore decided to compare the quality and the developmental ability, both in vivo and in vitro, of embryos reconstructed with either EF or PEM, the piezo device being used with varying setups. In addition to the record of the rate of development, we also compared the nuclear integrity in the blastomeres during the first cleavages as well as the morphological and cellular quality of the blastocysts. Our results show that the piezo-assisted micromanipulation, although allowing faster and more efficient reconstruction, should be used with precaution as it can induce DNA damage in the reconstructed embryos.

\section{Materials and Methods \\ Collection of in vivo fertilized embryos}

Eight- to ten-week-old B6D2 $F_{1}$ female mice were superovulated first by sequential administration of $10 \mathrm{IU}$ pregnant mare serum gonadotropin (Ningbo hormone production, Ningbo, China) and then, $48 \mathrm{~h}$ later, by $10 \mathrm{IU}$ human chorionic gonadotropin (hCG). The superovulated females were then mated with B6D2 $\mathrm{F}_{1}$ males after hCG injection. Fertilized embryos were collected 20-22 h after hCG injection and cultured in CZB (Chatot Ziomek Bavister) medium at $37{ }^{\circ} \mathrm{C}$ and $5 \%$ $\mathrm{CO}_{2}$ in air (in vivo $\mathrm{F}$ embryos).

Animals were handled according to the Guidelines for the Care and Use of Laboratory Animals established by the Beijing Association for Laboratory Animal Science.

\section{Mature oocytes and donor cell preparation}

B6D2 $F_{1}$ females (8-10 weeks old) were superovulated and cumulus-oocyte complexes were collected. Cumulus cells were removed using $300 \mathrm{U} / \mathrm{ml}$ hyaluronidase (ICN Pharmaceuticals, Costa Mesa, CA, USA). Oocytes were cultured in CZB medium before micromanipulation. Cumulus cell suspensions were washed with Hepes-CZB medium twice and stored at $4{ }^{\circ} \mathrm{C}$.

\section{Cloned embryos produced by direct injection method}

For direct injection, we used the 'one-step micromanipulation' technique developed for rat SCNT (Zhou et al. 2003): the cumulus nucleus was injected into a recipient oocyte and the meiotic metaphase plate was withdrawn while removing the pipette from the cytoplasm after injection. Twenty to thirty oocytes were placed into a drop of Hepes-CZB medium containing $5 \mu \mathrm{g} / \mathrm{ml}$ cytochalasin B (CB). Pipettes with an internal diameter of $8 \mu \mathrm{m}$ were used for the injection of the donor nucleus using a piezoelectric device (Prime Tech, Ibaraki, Japan). Three parameters influenced the strength of the piezoelectric pulses: $x$, pulse frequency; $y$, pulse intensity; and $z$, pulse duration. We used three setups of increasing strength for PEM: PEM010 = speed 0, intensity 1 , duration 0 impulse; PEM431= speed 4, intensity 3 , duration 4 impulses (estimated $1 \mathrm{~s}$ ); and PEM433= speed 4, intensity 3, duration 12 impulses (estimated $3 \mathrm{~s}$ ). For PEM010, no piezo pulse was used to break the membrane of the donor cumulus cell; instead, the cumulus membrane was broken by repeated aspiration in and out of the pipette, and only a light drill was used to break the oocyte membrane. PEM431 was the common setup used for breaking the zona pellucida and PEM433 an amplified one. After breaking the cumulus cell membrane, the cell is directly injected without removing the cytoplasm.

One to two hours after injection, the reconstructed embryos were activated by a 5 -h incubation in calciumfree CZB supplemented with $10 \mathrm{mM} \mathrm{SrCl}_{2}$ and $5 \mu \mathrm{g} / \mathrm{ml}$ $\mathrm{CB}$ before being extensively washed and cultured in $\mathrm{CZB}$ medium at $37{ }^{\circ} \mathrm{C}$ and $5 \% \mathrm{CO}_{2}$ in air for 4 days. Diploid parthenogenetic embryos activated by the same means were used as a control.

\section{Cloned embryos produced by the EF method}

For $\mathrm{EF}$, the metaphase plate together with the first polar body were removed from oocytes cultured in Hepes-CZB medium containing $5 \mu \mathrm{g} / \mathrm{ml}$ CB using a $12 \mu \mathrm{m}$ internal diameter pipette. A single cumulus cell was first introduced into the perivitelline space of each enucleated oocyte through a slit in the zonae pellucidae produced by piezo actuation and then electrically fused using one direct current pulse of $2400 \mathrm{~V} / \mathrm{cm}$ for $20 \mu \mathrm{s}$ in fusion medium (0.3 M mannitol, $0.1 \mathrm{mM}$ MgSO4, $0.1 \%$ polyvinylpyrrolidone (PVP), and $0.3 \% \mathrm{BSA}$ ). The reconstructed embryos were cultured in CZB medium for $1-2 \mathrm{~h}$ before being activated and cultured as described above.

\section{Intracytoplasmic sperm injection (ICSI)}

ICSI was carried out with a $10 \mu \mathrm{m}$ internal diameter piezo-driven micropipette as previously described (Kimura \& Yanagimachi 1995). The caudal epididymis of B6D2 males was excised and then punctured with a 25 gauge needle several times to release the contents 
into Krebs-Ringer bicarbonate solution (TYH). The sperm was resuspended in TYH at a density of 5-10 million $/ \mathrm{ml}$ before being incubated at $37{ }^{\circ} \mathrm{C}$ with $5 \% \mathrm{CO}_{2}$ in air for $45 \mathrm{~min}$ prior to ICSI. The sperm suspension was added to Hepes-CZB medium containing $5 \mu \mathrm{g} / \mathrm{ml} \mathrm{CB}$. Once the spermatozoa heads had been cut off by pressing their necks with injection pipettes, they were washed and injected into the oocytes using the piezo with PEM010 setup. After ICSI, the injected oocytes were cultured at $37{ }^{\circ} \mathrm{C}$ and $5 \% \mathrm{CO}_{2}$ in air.

\section{Immunostaining and laser-scanning confocal microscopy}

One- to four-cell stage embryos $(8,24$, and $48 \mathrm{~h}$ after activation for SCNT embryos) were fixed in PBS for 20 min with freshly prepared $2 \%$ paraformaldehyde and stained $10 \mathrm{~min}$ with $0.1 \mu \mathrm{g} / \mathrm{ml}$ Hoechst 33342 (Invitrogen, Carlsbad, CA, USA) to detect the DNA. The samples were observed using a Nikon fluorescence microscope and u.v. light.

After fixation, two-cell embryos were washed in $0.1 \%$ PVP/PBS thrice and permeabilized with $0.5 \%$ Triton $\mathrm{X}-100$ in PBS for 30 min before being blocked for $1 \mathrm{~h}$ in $2 \%$ BSA in PBS. Immunoreaction was performed for $12 \mathrm{~h}$ in the blocking solution containing rabbit polyclonal antibodies against $\gamma-\mathrm{H} 2 \mathrm{AX}$ (antiphospho-H2AX-Ser139; 1:100; Upstate Biotechnology, Lake Placid, NY, USA). After three washings in $0.1 \%$ PVP/PBS, the embryos were incubated with a fluorescein isothiolyanate (FITC)conjugated anti-rabbit secondary antibody (Santa Cruz Biotechnology, Santa Cruz, CA, USA) diluted 1:200 in the blocking solution and counterstained with propidium iodide (PI, $10 \mu \mathrm{g} / \mathrm{ml}$; Molecular Probes). The samples were observed with a LSM 510 META microscope (Zeiss, Oberkochen, Germany) using 488 and $535 \mathrm{~nm}$ lasers.

\section{Differential staining of the embryos}

The number of nuclei in the inner cell mass (ICM) and the trophectoderm (TE) cells of blastocysts were determined as previously described (Papaioannou \& Ebert 1988). At the end of the culture period ( $96 \mathrm{~h}$ after activation), the zonae pellucidae were removed by a brief exposure to $0.5 \%$ pronase and the embryos were rinsed in HepesCZB medium. They were then exposed to a 1:10 dilution of rabbit anti-mouse whole serum (Sigma) for $1 \mathrm{~h}$. After three 5-min rinses in Hepes-CZB medium, the embryos were exposed to a $1: 10$ dilution of guinea pig complement (Sigma) for $1 \mathrm{~h}$ at $37^{\circ} \mathrm{C}$ before the addition of PI $(10 \mu \mathrm{g} / \mathrm{ml})$ and Hoechst $33342(1 \mu \mathrm{g} / \mathrm{ml})$. They were then rinsed briefly in Hepes-CZB medium, mounted under cover slips, and examined using an inverted Nikon fluorescent microscope. Cell counts were made directly under the microscope. The nuclei of the ICM cells were labeled with only Hoechst 33342 and appeared blue, whereas the nuclei of the TE cells were stained with both fluorochromes and appeared pink. For each type of embryo, 20 (EF group) to 51 (ICSI group) embryos were used for counting.

\section{Apoptosis analysis with TUNEL assay}

In order to label fragmented 3' DNA (TUNEL, Clontech) as previously described (Moley et al. 1998), blastocysts were fixed in $2 \%$ paraformaldehyde, permeabilized with $0.5 \%$ Triton X-100, and then incubated with fluorescein-labeled dUTP and terminal transferase in the dark for $1 \mathrm{~h}$ at $37^{\circ} \mathrm{C}$. PI was used for nuclear counterstaining. Embryos were observed with a Zeiss confocal fluorescence microscope. At least, 31 (in vivo F embryos) and up to 68 (PEM010 group) embryos were analyzed.

\section{Embryo transfer}

Two- to four-cell stage SCNT embryos were transferred into oviducts of 0.5 day post coitum (dpc) pseudopregnant ICR mice. Cesarean section was carried out at $19.5 \mathrm{dpc}$.

\section{Statistical analysis}

The results were compared using SPSS software (Chicago, IL, USA). One-way ANOVA test was used when comparing the number of embryos or number of cells. All percentages were subjected to arcsin (square root) transformation. The transformed data were analyzed by least significant difference test $(P>0.05$ after testing the homogeneity of variance) or Dunnett's $C$ test $(P<0.05$ after testing the homogeneity of variance). $\chi^{2}$ test $(P<0.05)$ was used to analyze the results presented in Table 5.

\section{Results}

We compared the development of NT embryos reconstructed either by EF or by injection (PEM). For the injection method, three piezo-pulse parameter setups of increasing strength were used. In vivo fertilized (in vivo F) embryos were used as baseline control, whereas ICSI embryos were used as a control for injection and manipulation and parthenotes for activation.

\section{Comparison of NT efficiency with the PEM and EF methods}

We compared the reconstruction and activation efficiencies from PEM and EF using cumulus as donor cells (Table 1). In the PEM group, more than $90 \%$ of manipulated oocytes survived the injection, whereas the rate was three times lower when embryos 
Table 1 Efficiency of nuclear transfer in the mouse by piezoelectric microinjection (PEM) and electrofusion (EF) methods.

\begin{tabular}{|c|c|c|c|c|c|}
\hline & & No. of oocytes & No. of replicates & $\begin{array}{l}\text { No. of reconstructed } \\
\text { embryos }(\%)\end{array}$ & $\begin{array}{l}\text { No. of activated } \\
\text { embryos }(\%)^{\mathrm{a}}\end{array}$ \\
\hline \multirow[t]{3}{*}{ Injection } & PEM010 & 225 & 7 & $207(92.0)^{*}$ & $175(84.5)^{*}$ \\
\hline & PEM431 & 242 & 7 & $226(93.4)^{*}$ & $192(85.0)^{*}$ \\
\hline & PEM433 & 208 & 7 & $191(91.8)^{*}$ & $167(87.4)^{*}$ \\
\hline Electrofusion & & 322 & 7 & $110(34.2)^{\dagger}$ & $99(90.0)^{*}$ \\
\hline
\end{tabular}

${ }^{*}{ }^{\dagger}$ Numbers with different superscripts denote values that differ significantly within a column $(P<0.05)$.

apercentage of activated oocytes were calculated based on the number of reconstructed embryos.

were reconstructed by EF (34\%). In both cases, all the reconstructed embryos were activated with the same high efficiency (84-90\%). The rates were slightly lower than for parthenogenetic embryos $(95.6 \pm 3.2 \%$, $P<0.05$, data not shown). Our results show that the use of the 'one-step' method for nucleus injection and spindle removal does not impair the reconstruction efficiency.

\section{In vitro development of NT embryos}

The cleavage rate and blastocyst formation of embryos after reconstruction by EF or PEM were evaluated in vitro. In all groups, the first cleavage rate was high, ranging from 94 to $100 \%$, with no statistical difference between NT, fertilized, and parthenogenetic embryos (Table 2). However, differences appeared at the morula stage, with less NT embryos reaching this stage (up to $88.9 \%$ ) than fertilized $(95.6 \%$ for in vivo $\mathrm{F}$ and $97.8 \%$ for ICSI) or parthenogenetic (94.4\%) control embryos. More remarkably, it appears that the method of NT affects the developmental potential of the embryos. The rate of morula and blastocysts was indeed higher in the EF group (88.9 and $56.7 \%$ respectively) than in the PEM 431 and PEM433 groups (73.4-74.4 and 39.8-42.1\% respectively).

We also noticed that fewer ICSI embryos developed to the blastocyst stage $(68.5 \%)$ than in vivo $\mathrm{F}(94.3 \%)$ or parthenote $(87.2 \%)$ embryos did, although there was no difference at the morula stage. This result suggests that the transition from morula to blastocyst is affected by micromanipulation of matured oocytes.

\section{DNA damage in early cloned embryos}

Since the method to introduce the donor nucleus appeared to influence the rate of pre-implantation development, we investigated whether this could be related to nuclear damage. DNA staining with Hoechst 33342 revealed some small DNA patches in the cytoplasm of some embryonic blastomeres, in addition to the major nucleus (Fig. 1). These micronuclei were detected not only in the cloned embryos but also in some controls (Table 3). However, none of the controls, EF, or PEM010 groups presented micronuclei at the one-cell stage in contrast to NT embryos produced by PEM431 and PEM433. As the PEM embryos developed, the incidence of micronuclei formation increased, affecting half of the two- and four-cell embryos in the PEM433 group. The majority of PEM embryos blocked at the twocell stage displayed micronuclei (Table 3).

To further investigate the nature of these micronuclei, we explored the presence of DNA double-strand fragments (DSFs). It is well known that in response to DNA damage, a rapid modification of histone composition within the chromatin leads to the accumulation of phospho-H2AX (Sedelnikova et al. 2002). The 1:1 correspondence between the number of $\gamma-\mathrm{H} 2 \mathrm{AX}$ foci and the number of DSFs makes anti- $\gamma-\mathrm{H} 2 \mathrm{AX}$-specific antibodies good markers of DSFs. Using this antibody, we found $\gamma-\mathrm{H} 2 \mathrm{AX}$ positive foci in PEM NT embryos either co-localized with the micronuclei DNA staining or within some major nuclei (Fig. 2B-D). Strikingly, the number of $\gamma-\mathrm{H} 2 \mathrm{AX}$ positive foci increased with the strength of the piezo pulse used for PEM. In comparison, few, if any, positive foci were present in EF embryos and

Table 2 Pre-implantation development of murine reconstructed embryos produced by electrofusion or NT injection methods.

\begin{tabular}{|c|c|c|c|c|c|}
\hline & \multirow[b]{2}{*}{ No. of one-cell embryos } & \multirow[b]{2}{*}{ No. of replicates } & \multicolumn{3}{|c|}{ Development to (\%) } \\
\hline & & & Two-cell & Morula & Blastocyst \\
\hline PEM010 & 175 & 7 & $95.3 \pm 3.0$ & $69.8 \pm 3.2^{\ddagger}$ & $45.5 \pm 7.0^{\ddagger, \S}$ \\
\hline PEM431 & 192 & 7 & $93.7 \pm 4.5$ & $73.4 \pm 13.4^{\neq}$ & $39.8 \pm 5.3^{\S}$ \\
\hline PEM433 & 167 & 7 & $95.9 \pm 4.0$ & $74.4 \pm 7.4^{\neq}$ & $42.1 \pm 11.8^{\S}$ \\
\hline $\mathrm{EF}$ & 99 & 7 & $96.3 \pm 5.9$ & $88.9 \pm 9.1^{+}$ & $56.7 \pm 1.9^{\ddagger}$ \\
\hline $\mathrm{Pa}$ & 79 & 4 & 100 & $94.4 \pm 4.1^{*}$ & $87.2 \pm 4.2^{+}$ \\
\hline In vivo $\mathrm{F}$ & 88 & 4 & $98.9+2.4$ & $97.8+4.7 *$ & $94.3+6.8^{*}$ \\
\hline ICSI & 240 & 5 & $99.6 \pm 1.0$ & $95.6 \pm 4.6^{*}$ & $68.5 \pm 3.0^{\ddagger}$ \\
\hline
\end{tabular}

$\mathrm{Pa}$, parthenote embryos. ${ }^{*},+, \neq$, Numbers with different superscripts denote values that differ significantly within a column (one-way ANOVA, $P<0.05)$. 

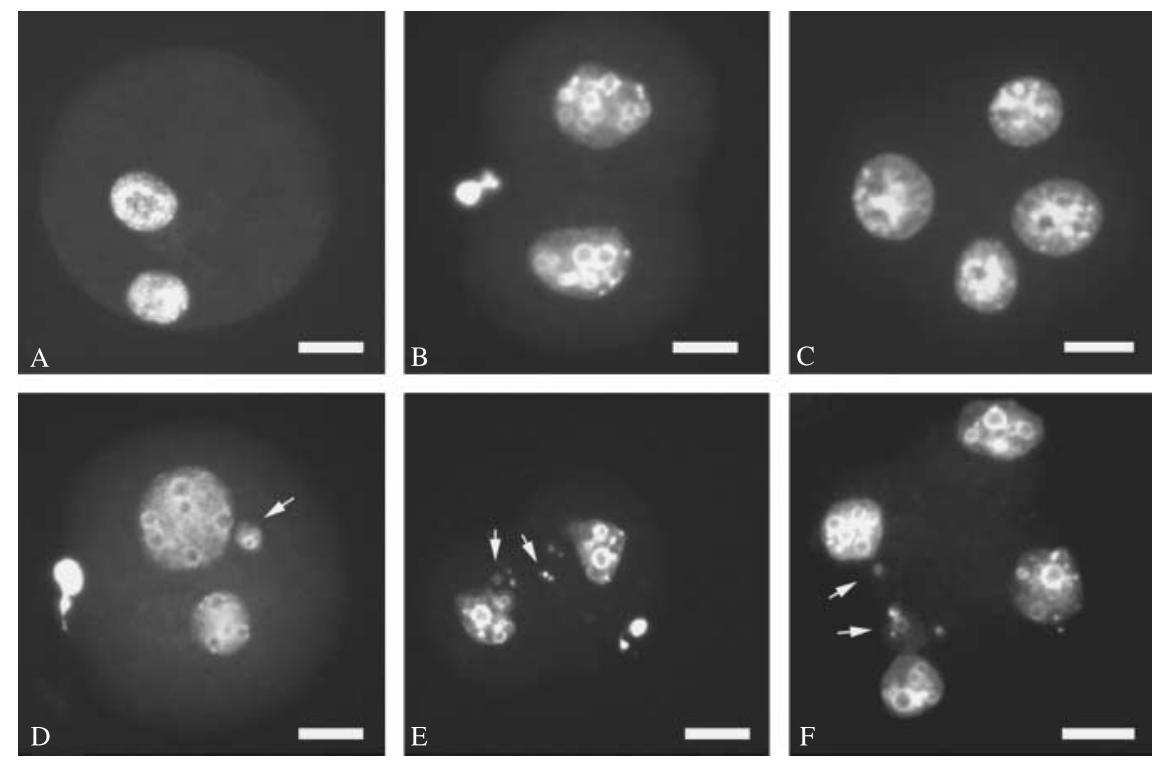

Figure 1 DNA staining with Hoechst 33342 revealed the presence of micronuclei in oneto four-cell NT embryos. (A-C) Parthenogenetic controls. (D-F) SCNT embryos produced by PEM431. (A and D) One-, (B and E), two-, and ( $\mathrm{C}$ and $\mathrm{F}$ ) four-cell embryos. Scale bar: $20 \mu \mathrm{m}$. Arrows show the micronuclei outside the major nucleus. controls (Fig. 2A). These observations indicate that the formation of micronuclei is caused by DSFs as a consequence of high piezo-pulse parameters in the process of nuclear transfer.

\section{Embryo quality assessment by differential staining and TUNEL assay}

In view of the high incidence of micronuclei and DSFs in the PEM NT embryos, we hypothesized that the rate of apoptosis could be higher in these embryos. Apoptosis has been considered to be a normal process in pre-implantation embryos to eliminate cells with nuclear or chromosomal abnormalities (Hardy 1997). To test this hypothesis, we performed TUNEL assays at the blastocyst stage. The blastocyst cell number and the allocation of cells to the ICM are important parameters in assessing the blastocyst quality (Van Soom et al. 1997, Koo et al. 2002). By differential staining, we evaluated the total number of cells and the ratio of ICM cells in NT and control blastocysts. Results are summarized in Table 4.
Embryos produced with the use of piezo injection (ICSI and PEM NT) displayed a statistically significant lower number of blastocyst cells (33-39.2 cells when compared with 46.7 cells for $F$ embryos on average). In contrast, blastocyst cell numbers were similar in EF embryos ( 42) and parthenote controls ( 46). The allocation of cells to the ICM differed significantly in all manipulated and/or artificially activated embryos (from 20.9 to $29.3 \%$ when compared with $F(36.5 \%)$ embryos).

The rate of apoptosis was calculated by dividing the number of cells with TUNEL positive nuclei by the total blastocyst cell number. As shown in Table 4, blastocysts are distributed into three groups that differ significantly. The highest rate of apoptosis was found within the PEM431 and 433 NT embryos, with up to $30.3 \%$ apoptotic cells. The rate of apoptosis in other NT embryos (PEM010 and EF) was similar to that of the parthenote ones $(17 \%)$, while higher than both groups of fertilized embryos (in vivo $\mathrm{F}$ $6.5 \%$ and ICSI $10 \%$ ).

Table 3 Micronuclei detection during pre-implantation development of mouse embryos.

\begin{tabular}{|c|c|c|c|c|}
\hline & \multicolumn{4}{|c|}{ No. of NT embryos with micronuclei/No. observed (\%) } \\
\hline & One-cell embryos $\left(8 \mathrm{~h}^{\mathrm{a}}\right)$ & Two-cell embryos $\left(24 \mathrm{~h}^{\mathrm{a}}\right)$ & Four-cell embryos $\left(48 \mathrm{~h}^{\mathrm{a}}\right)$ & Two-cell blocked embryos $\left(48 \mathrm{~h}^{\mathrm{a}}\right)$ \\
\hline PEM010 & $0 / 22(0)$ & 2/51 (3.92) & 3/16 (18.75) & $16 / 18(88.89)^{+}$ \\
\hline PEM431 & $1 / 24(4.2)$ & 4/52 (7.69) & 7/21 (33.33) & $10 / 14(71.43)^{\dagger}$ \\
\hline PEM433 & 4/19 (21.1) & $23 / 47(48.94)^{*}$ & $14 / 26(53.85)^{*}$ & $10 / 12(83.33)^{+}$ \\
\hline $\mathrm{EF}$ & 0/23 (0) & $0 / 20(0)$ & $1 / 19(5.26)$ & $2 / 8(25)^{\ddagger}$ \\
\hline $\mathrm{Pa}$ & $0 / 26(0)$ & $1 / 29(3.45)$ & 5/36 (13.89) & $3 / 15(20)^{\ddagger}$ \\
\hline In vivo $\mathrm{F}$ & $0 / 18(0)$ & $0 / 20(0)$ & $1 / 15(6.67)$ & $1 / 4(25)^{b}$ \\
\hline ICSI & 0/18 (0) & $2 / 18(11.1)$ & 2/19 (10.5) & $3 / 11(27.3)^{\neq}$ \\
\hline
\end{tabular}

*Statistically different from the others within the column (Fisher's exact test, $P<0.001)$. ${ }^{\dagger}$ Differs significantly from ${ }^{\ddagger}\left(\chi^{2}\right.$ test, $\left.P<0.001\right)$.

a Hours post-activation (for NT embryos). ${ }^{b}$ Statistics not applicable. 

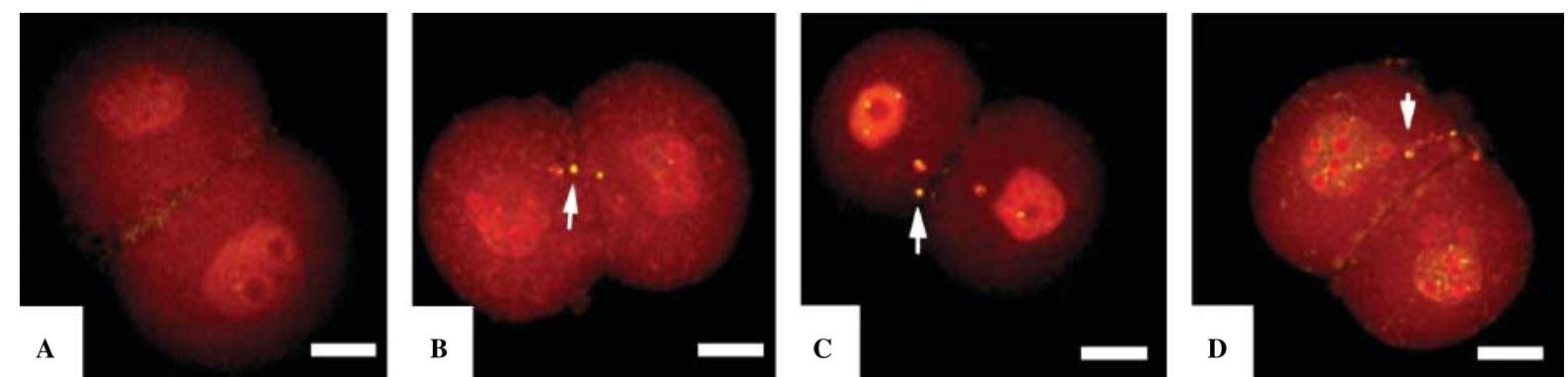

Figure 2 DNA double-strand fragments (DSFs) in two-cell embryos revealed by $\gamma-\mathrm{H} 2 \mathrm{AX}$ staining. (A) Control parthenogenetic embryos. (B-D) NT embryos were produced with PEM010 (B), PEM431 (C), and PEM433 (D) piezo-pulse parameters. Due to DNA counterstaining with propidium iodide (in red), spots of $\gamma-\mathrm{H} 2 \mathrm{AX}$ appear yellow. Scale bar: $20 \mu \mathrm{m}$. Arrows point to DSFs outside the major nucleus, but some DSFs can also be seen inside it.

\section{Full-term development and peri-implantation survival of NT embryos}

We then decided to investigate the influence of the reconstruction method used in in vivo development. As the high rate of apoptotic cells in NT embryos reconstructed with strong piezoelectric pulses (PEM431 and PEM433) probably compromised their developmental competency, in this experiment we used the milder PEM010 setup to compare injection versus fusion. Two- or four-cell NT embryos were transferred into E0.5 pseudo-pregnant recipients and pups were delivered by cesarean section at E19 (Table 5). As the rate of in vitro development from two- to four-cell stage was similarly high (about 90\% for both PEM and EF NT embryos, data not shown), the results of the in vivo development were pooled. Remarkably, the rates of pregnancy and delivery of living pups were more than three times higher for the EF than for the PEM group. However, when the rate of development to term is computed from the number of oocytes manipulated (rate of reconstruction $\times$ rate of activation $\times$ rate of two-cell $\times$ rate of development to term), the advantage of using the EF method is less obvious: $0.74 \%$ of the manipulated oocytes in the $\mathrm{EF}$ group give rise to a pup, when compared with $0.49 \%$ for oocytes from the PEM group.

\section{Discussion}

Two methods have been used to reconstruct embryos by SCNT, EF, or PEM, both having given rise to live animals. During nuclear transfer by EF, a whole cell is fused to the oocyte cytoplasm. It does not require an extensive manipulation of the donor cell. By contrast, the PEM procedure requires the use of piezo pulses to break the donor cell membrane and to penetrate the oocyte. In the present study, we have evaluated the impact of such mechanical stresses on the development of NT embryos reconstructed by injection of cumulus nuclei and compared it with that of NT embryos reconstructed by fusion. The use of different strengths of piezoelectric pulses and of three different types of control embryos has allowed us to distinguish the effects of the following parameters: embryo manipulation, efficiency of NT, injection procedure, piezo-pulse strength, and activation.

Our results show that the efficiency of reconstruction is about three times lower with the EF method, probably owing to the small size of the cumulus donor cells. With fibroblasts as donors, Ogura et al. (2000) have reported a higher rate of fusion, although the efficiency of reconstruction was still lower than after injection. Apart from the surface of contact between the two cells, fusion also depends on the characteristics of the membrane. Powell et al. (2004) suggest that the EF

Table 4 Blastocyst quality in terms of total cell number, inner cell mass (ICM) allocation, and apoptotic rates.

\begin{tabular}{lcccccc}
\hline & $\begin{array}{c}\text { No. of } \\
\text { blastocysts }\end{array}$ & $\begin{array}{c}\text { Total blastocyst } \\
\text { cell number }\end{array}$ & $\begin{array}{c}\text { ICM cell } \\
\text { number }\end{array}$ & $\begin{array}{c}\text { Ratio of } \\
\text { ICM cells }(\%)\end{array}$ & $\begin{array}{c}\text { No. of } \\
\text { blastocysts }\end{array}$ & $\begin{array}{c}\text { Rate of } \\
\text { apoptosis }(\%)\end{array}$ \\
\hline PEM010 & 42 & $38.1 \pm 11.2^{+, \neq}$ & $9.4 \pm 3.8^{+}$ & $25.6 \pm 9.4^{+}$ & 31 & $17.4 \pm 8.8^{+}$ \\
PEM431 & 40 & $35.7 \pm 10.6^{\ddagger}$ & $9.6 \pm 4.6^{+}$ & $26.9 \pm 10.7^{+}$ & 39 & $26.1 \pm 9.5^{\ddagger}$ \\
PEM433 & 41 & $33.0 \pm 11.1^{\ddagger}$ & $8.7 \pm 4.7^{+}$ & $25.9 \pm 10.4^{+}$ & 33 & $30.3 \pm 12.2^{\ddagger}$ \\
EF & 20 & $42.0 \pm 9.4^{*}$ & $9.4 \pm 4.2^{+}$ & $20.9 \pm 5.4^{+}$ & 38 & $17.1 \pm 6.7^{+}$ \\
Pa & 79 & $46.0 \pm 13.2^{*}$ & $13.2 \pm 5.9^{*}$ & $29.3 \pm 12.0^{+}$ & 42 & $17.0 \pm 7.4^{+}$ \\
In vivo F & 58 & $46.7 \pm 11.0^{*}$ & $16.6 \pm 5.9^{*}$ & $36.5 \pm 13.8^{*}$ & 44 & $6.5 \pm 6.9^{*}$ \\
ICSI & 58 & $39.2 \pm 10.8^{+}$ & $9.9 \pm 5.0^{+}$ & $25.1 \pm 11.1^{+}$ & 69 & $10.0 \pm 7.6^{*}$
\end{tabular}

${ }^{*,+, \neq}$ Numbers with different superscripts denote values that differ significantly within a column. ${ }^{*}$ versus $+; \dagger$ versus $\neq, P<0.05 ;{ }^{*}$ versus $\ddagger(O n e-w a y$ ANOVA, $P<0.01)$. Data of the ICM cell number were analyzed by Dunnett's $C$ test $(P<0.05)$. 
Table 5 Development to term of NT mouse embryos reconstructed with cumulus nuclei.

\begin{tabular}{lccccc}
\hline & $\begin{array}{c}\text { No. of two-cell } \\
\text { NT embryos }\end{array}$ & $\begin{array}{c}\text { No. of } \\
\text { recipients }\end{array}$ & $\begin{array}{c}\text { No. of implantation } \\
\text { sites }(\%)\end{array}$ & $\begin{array}{c}\text { No. of } \\
\text { pups }(\%)\end{array}$ & $\begin{array}{c}\text { No. of surviving } \\
\text { animals }^{\mathrm{a}}\end{array}$ \\
\hline PEM & 896 & 38 & $24(2.7)^{*}$ & $6(0.67)^{*}$ & 4 \\
EF & 238 & 11 & $24(10.1)^{\dagger}$ & $6(2.52)^{+}$ & 4 \\
\hline
\end{tabular}

${ }^{*}{ }^{\dagger}$ Numbers with different superscripts denote values that differ significantly within a column. ${ }^{*}$ versus $+\left(\chi^{2}\right.$ test, $\left.P<0.02\right)$.

${ }^{\mathrm{a} A f t e r} 1$ week.

efficiency of fibroblasts is variable from one individual animal to the other, and this difference enlarges when different oxygen concentrations are used for the culture of donor cells. Therefore, further studies will be necessary to evaluate the ability of donor cells from different tissues and individuals to fuse.

Nuclei of cumulus cells are in G0/G1 stage and have a loose structure (Schuetz et al. 1996). After a donor cell is aspirated into the injection pipette, piezo pulses are used to break the cell membrane (for PEM431 and PEM433) and then to break the oocyte membrane. When they are submitted to such shear force produced by the piezo pulses, the DNA double-strand structure of the cumulus nuclei may be altered. When the nuclei with such DNA strand fragments are injected into enucleated oocytes and remodeled, DNA fragments may be repaired or remain as such. We indeed found some spots of DNA, or 'micronuclei', outside the major nucleus of the blastomeres, which were identified as DSFs by the presence of phosphorylated $\mathrm{H} 2 \mathrm{AX}$. Although these micronuclei were found even in fertilized embryos, which may be caused by the in vitro culture, the rate of embryos affected by these DSFs is clearly increased when high piezo-pulse strength is used. As checkpoints during the cell cycle ensure the integrity of genome through DNA replication and segregation (Nyberg et al. 2002, Qin \& Li 2003), damaged blastomeres with important DNA fragmentation that cannot be repaired will therefore not cleave. Enhanced piezo pulse in nuclear transfer that cause important DNA breaks might thus explain why the majority of two-cell blocked embryos produced by injection have micronuclei.

Observing the rate of development to blastocyst stage and the morphology of the blastocysts is the initial criterion in evaluating the quality of NT embryos. In this study, we have found that for all NT groups, the transition from morula to blastocyst is a difficult milestone, as more than one-third of the morulae do not form blastocysts. Among control groups, such an arrest in development is observed only for ICSI embryos. This finding suggests that manipulation and/or injection affect this first differentiation event, the transition from morula to blastocyst. This effect is not apparent in most reports where the morula and blastocyst numbers are combined.

Apoptosis is another criterion of quality as this process is used to eliminate cells with nuclear or chromosomal abnormalities (Hardy 1997). It clearly appears that the quality of the PEM blastocysts is greatly affected in terms of apoptotic blastomeres when increasing strengths of piezo pulse are used, although the blastocyst rates of embryos reconstructed by PEM are only slightly lower than those obtained after EF. Thus, even if some early embryos can cleave in the presence of DNA fragments, the blastomeres with such abnormal nuclei may be eliminated by the process of apoptosis. The increase of apoptosis in NT blastocysts is also correlated with a decrease in the total cell number and with the increasing number of embryos showing micronuclei. This observation suggests that either these NT blastocysts grow more slowly or some blastomeres with abnormal nuclei (micronuclei) have already been eliminated before the blastocyst stage. Indeed, a comparison of apoptosis rate between fertilized embryos has revealed significant differences between strains and culture media (Kamjoo et al. 2002).

Finally, another criterion to evaluate blastocyst quality is the ICM/TE cell ratio. In this study, we found that in comparison with $\mathrm{F}$ embryos, in vitro manipulation and/or chemical activation also decrease the number of ICM cells when compared with that of $\mathrm{F}$ embryos, even when the total cell number is unaffected, as for parthenogenetic embryos. In all NT groups, the ratio of ICM is similar, suggesting that the process of cell allocation to the ICM is not directly affected by the NT procedure as previously observed with ES cells as donors (Zhou et al. 2001).

Taking into account all these criteria - rate of apoptotic cells, ICM allocation, and total cell number the blastocysts from the EF and PEM010 groups displayed similar qualities. However, when transferred in vivo at the two- to four-cell stage, EF embryos had a higher ability to implant and develop to term (threefold higher) than PEM embryos. A major difference between EF and PEM010 method is that in the first one the donor nucleus is subjected to mechanical stress before injection. By moving in and out of the pipette until breakage of the cytoplasmic membrane, the repeated change in cell shape should be transduced to the nucleus and thus the configuration of the chromatin may be somehow affected (Maxwell \& Hendzel 2001, Vergani et al. 2004). In addition, while in the pipette, the nucleus is subjected to the slight drill necessary to penetrate the oocyte membrane. Even this light piezo pulse may disturb the nuclear architecture. Another difference between the two procedures is that the injection pipette penetrates deeply into the ooplasm, which would disturb 
and/or damage some intracellular structures. This confirms that rate of development and blastocyst morphology do not foreshadow post-implantation development ability (Jouneau et al. 2006) and also suggests that the expression of genes crucial for postimplantation development may be affected by the method of embryo reconstruction.

In conclusion, our results show that the development of NT embryos to blastocyst stage and the quality of these blastocysts are impaired when strong piezo pulses are used during the injection procedure and that the fullterm development is also affected by the use of piezodriven injection. The use of the piezo device, although very efficient for injection of a donor nucleus (NT) or a sperm head (ICSI), should thus be considered cautiously and parameters should be set as low as possible.

\section{Acknowledgements}

Financial supports were from China National Basic Research Program 2006CB701501, PRA B 04-04 and The National Science Foundation of China 30300176 and 30525040. The authors declare that there is no conflict of interest that would prejudice the impartiality of this scientific work.

\section{References}

Galli C, Lagutina I, Vassiliev I, Duchi R \& Lazzari G 2002 Comparison of microinjection (piezo-electric) and cell fusion for nuclear transfer success with different cell types in cattle. Cloning Stem Cells $\mathbf{4}$ 189-196.

Hardy K 1997 Cell death in the mammalian blastocyst. Molecular Human Reproduction 3 919-925.

Jouneau A \& Renard JP 2003 Reprogramming in nuclear transfer. Current Opinion in Genetics and Development 13 486-491.

Jouneau A, Zhou Q, Camus A, Brochard V, Maulny L, Collignon J \& Renard J-P 2006 Developmental abnormalities of NT mouse embryos appear early after implantation. Development 133 1597-1607.

Kamjoo M, Brison DR \& Kimber SJ 2002 Apoptosis in the preimplantation mouse embryo: effect of strain difference and in vitro culture. Molecular Reproduction and Development 61 67-77.

Kimura Y \& Yanagimachi R 1995 Intracytoplasmic sperm injection in the mouse. Biology of Reproduction 52 709-720.

Koo DB, Kang YK, Choi YH, Park JS, Kim HN, Oh KB, Son DS, Park H, Lee KK \& Han YM 2002 Aberrant allocations of inner cell mass and trophectoderm cells in bovine nuclear transfer blastocysts. Biology of Reproduction 67 487-492.

Latham KE 2004 Cloning: questions answered and unsolved. Differentiation 72 11-22.

Maxwell CA \& Hendzel MJ 2001 The integration of tissue structure and nuclear function. Biochemistry and Cell Biology 79 267-274.

Moley KH, Chi MM, Knudson CM, Korsmeyer SJ \& Mueckler MM 1998 Hyperglycemia induces apoptosis in pre-implantation embryos through cell death effector pathways. Nature Medicine 4 1421-1424.
Nyberg KA, Michelson RJ, Putnam CW \& Weinert TA 2002 Toward maintaining the genome: DNA damage and replication checkpoints. Annual Review of Genetics 36 617-656.

Ogura A, Inoue K, Takano K, Wakayama T \& Yanagimachi R 2000 Birth of mice after nuclear transfer by electrofusion using tail tip cells. Molecular Reproduction and Development 57 55-59.

Papaioannou VE \& Ebert KM 1988 The preimplantation pig embryo: cell number and allocation to trophectoderm and inner cell mass of the blastocyst in vivo and in vitro. Development 102 793-803.

Perry AC 2004 Nuclear transfer cloning and the United Nations. Nature Biotechnology 22 1506-1508.

Perry AC \& Wakayama T 2002 Untimely ends and new beginnings in mouse cloning. Nature Genetics 30 243-244.

Powell AM, Talbot NC, Wells KD, Kerr DE, Pursel VG \& Wall RJ 2004 Cell donor influences success of producing cattle by somatic cell nuclear transfer. Biology of Reproduction 71 210-216.

Qin J \& Li L 2003 Molecular anatomy of the DNA damage and replication checkpoints. Radiation Research 159 139-148.

Schuetz AW, Whittingham DG \& Snowden R 1996 Alterations in the cell cycle of mouse cumulus granulosa cells during expansion and mucification in vivo and in vitro. Reproduction, Fertility, and Development 8 935-943.

Sedelnikova OA, Rogakou EP, Panyutin IG \& Bonner WM 2002 Quantitative detection of (125)IdU-induced DNA double-strand breaks with gamma-H2AX antibody. Radiation Research 158 486-492.

Solter D 2000 Mammalian cloning: advances and limitations. Nature Reviews. Genetics 1 199-207.

Van Soom A, Ysebaert M \& de Kruif A 1997 Relationship between timing of development, morula morphology, and cell allocation to inner cell mass and trophectoderm in in vitro-produced bovine embryos. Molecular Reproduction and Development 47 47-56.

Van Thuan N, Wakayama S, Kishigami S, Ohta H, Hikichi T, Mizutani E, Bui HT \& Wakayama T 2006 Injection of somatic cell cytoplasm into oocytes before ICSI impairs full-term development and increases placental weight in mice. Biology of Reproduction 74 865-873.

Vergani L, Grattarola M \& Nicolini C 2004 Modifications of chromatin structure and gene expression following induced alterations of cellular shape. International Journal of Biochemistry and Cell Biology 36 1447-1461.

Wakayama T, Perry ACF, Zuccotti M, Johnson KR \& Yanagimachi $R$ 1998 Full-term development of mice from enucleated oocytes injected with cumulus cell nuclei. Nature 394 369-374.

Yabuuchi A, Yasuda Y, Kato Y \& Tsunoda Y 2004 Effects of nuclear transfer procedures on ES cell cloning efficiency in the mouse. Journal of Reproduction and Development 50 263-268.

Zhou Q, Jouneau A, Brochard V, Adenot P \& Renard JP 2001 Developmental potential of mouse embryos reconstructed from metaphase embryonic stem cell nuclei. Biology of Reproduction 65 412-419.

Zhou Q, Renard JP, Le Friec G, Brochard V, Beaujean N, Cherifi Y, Fraichard A \& Cozzi J 2003 Generation of fertile cloned rats by regulating oocyte activation. Science 3021179.

Received 7 December 2006

First decision 9 January 2007

Accepted 6 February 2007 